OPEN ACCESS

Check for updates

\title{
Hospital volume and outcomes for acute pulmonary embolism: multinational population based cohort study
}

\author{
David Jiménez, ${ }^{1,2}$ Behnood Bikdeli, ${ }^{3,4,5}$ Andrés Quezada, ${ }^{1}$ Alfonso Muriel, ${ }^{6}$ José Luis Lobo, ${ }^{7}$ \\ Javier de Miguel-Diez, ${ }^{8}$ Luis Jara-Palomares, ${ }^{9}$ Pedro Ruiz-Artacho, ${ }^{10}$ Roger D Yusen, ${ }^{11}$ \\ Manuel Monreal, ${ }^{12,13}$ for the RIETE investigators
}

For numbered affiliations see end of the article.

Correspondence to: D Jiménez djimenez.hrc@gmail.com (or @DJC6998 on Twitter; ORCID 0000-0002-4571-7721)

Additional material is published online only. To view please visit the journal online.

Cite this as: BMJ 2019;366:14416 http://dx.doi.org/10.1136/bmj.l4416

Accepted: 4 June 2019

\section{ABSTRACT}

OBJECTIVES

To evaluate the association between experience in the management of acute pulmonary embolism, reflected by hospital case volume, and mortality.

\section{DESIGN}

Multinational population based cohort study using data from the Registro Informatizado de la Enfermedad TromboEmbólica (RIETE) registry between 1 January 2001 and 31 August 2018.

SETTING

353 hospitals in 16 countries.

PARTICIPANTS

39257 consecutive patients with confirmed diagnosis of acute symptomatic pulmonary embolism.

MAIN OUTCOME MEASURE

Pulmonary embolism related mortality within 30 days after diagnosis of the condition.

RESULTS

Patients with acute symptomatic pulmonary embolism admitted to high volume hospitals ( $>40$ pulmonary embolisms per year) had a higher burden of comorbidities. A significant inverse association was seen between annual hospital volume and pulmonary embolism related mortality. Admission to hospitals in the highest quarter (that is, $>40$ pulmonary embolisms per year) was associated with a $44 \%$ reduction in the adjusted odds of pulmonary embolism related mortality at 30 days compared with admission to hospitals in the lowest quarter ( 15 pulmonary embolisms per year; adjusted risk $1.3 \%$ v 2.3\%; adjusted odds ratio 0.56 (95\% confidence interval 0.33 to 0.95$) ; P=0.03)$. Results were consistent in all sensitivity analyses. All cause mortality at 30 days was not significantly reduced between the two quarters (adjusted odds ratio 0.78 (0.50 to 1.22); $\mathrm{P}=0.28$ ). Survivors showed little change in the odds of recurrent venous thromboembolism (odds ratio 0.76

\section{WHAT IS ALREADY KNOWN ON THIS TOPIC}

The number of patients treated in a hospital is a well established determinant of outcomes after different surgical conditions

However, the contribution of experience to survival after acute pulmonary embolism is less well understood

\section{WHAT THIS STUDY ADDS}

In patients with acute symptomatic pulmonary embolism, annual hospital volume had a significantly inverse association with mortality related to pulmonary embolism

Admission to lower volume hospitals was associated with significantly increased odds of adjusted mortality related to pulmonary embolism at 30 days
(0.49 to 1.19$))$ or major bleeding (1.07 (0.77 to 1.47$)$ ) between the low and high volume hospitals.

\section{CONCLUSIONS}

In patients with acute symptomatic pulmonary embolism, admission to high volume hospitals was associated with significant reductions in adjusted pulmonary embolism related mortality at 30 days. These findings could have implications for management strategies.

\section{Introduction}

Pulmonary embolism remains a worldwide major health problem. ${ }^{1}$ It is among the most common causes of vascular death after myocardial infarction and stroke, and is the leading preventable cause of death in patients in hospital. ${ }^{2}$ The number of patients treated in a hospital is a well established determinant of outcomes after different medical and surgical conditions. ${ }^{3-5}$ For acute symptomatic pulmonary embolism, however, the contribution of experience to survival is less well understood. ${ }^{6}$ Treatment of pulmonary embolism is complex and requires considerable clinical skills. Patients with pulmonary embolism can present with a wide variety of clinical manifestations and could develop several complications that require timely recognition and treatment. The optimal treatment for patients with pulmonary embolism has markedly evolved over the past decade. ${ }^{7-10}$ Thus, there is a clinical priority to determine whether patients admitted to hospitals that only occasionally treat patients with pulmonary embolism have similar outcomes to those admitted to hospitals that treat patients with pulmonary embolism more frequently.

The Registro Informatizado de la Enfermedad TromboEmbólica (RIETE) Registry is an ongoing, multicentre, international, prospective registry of consecutive patients with symptomatic, objectively confirmed, acute venous thromboembolism. ${ }^{11-13}$ We hypothesised that experience in the management of acute pulmonary embolism, reflected by hospital case volume, would be significantly associated with a reduction in pulmonary embolism related mortality at 30 days, after adjustment for differences in the patient case mix and hospital status (university based or not).

\section{Methods}

\section{Study design}

For this study, we used the data from the RIETE registry, which prospectively collects information on patients with confirmed acute venous thromboembolism (ClinicalTrials.gov NCT02832245). All patients provided written or oral consent for participation in 
the registry in accordance with local ethics committee requirements. Previous publications have described the design and conduct of the RIETE registry. ${ }^{14} 15$ Briefly, at each participating RIETE site, investigators enrolled consecutive patients with acute venous thromboembolism. To ensure the reliability of coding and data entry, trained monitors periodically visited each participating hospital and compared the information in a random sample of hospital charts with the information entered into the RIETE database. RIETE also uses electronic data monitoring to prevent inconsistent or implausible values. In fact, previous studies have shown that data from RIETE closely represents that of multicentre administrative data, further supporting the representativeness and the validity of the data elements. ${ }^{16}$

\section{Patient selection}

Confirmatory testing for pulmonary embolism consisted of high probability ventilation-perfusion scintigraphy ${ }^{17}$; positive computed tomography (CT) pulmonary angiography for pulmonary embolism ${ }^{18}$; or venous compression ultrasonography of the lower limb that was positive for proximal deep vein thrombosis (DVT) in a patient presenting with chest symptoms. ${ }^{19}$ This study included patients who were enrolled in the RIETE registry and had a diagnosis of acute, symptomatic pulmonary embolism from 1 January 2001 to 31 August 2018.

\section{Hospital volume}

We defined hospital volume as the mean number of patients with pulmonary embolism per year admitted to each hospital during its participation in the RIETE registry. Accurate case ascertainment is essential for clinical registries to be valid and representative. We assessed case ascertainment in the RIETE registry by linking 16 random Spanish registry hospitals (four per hospital volume quarter) to the Spanish National Patient Registry during 2017 (see methods section in the supplementary appendix). Firstly, we used volume as a continuous variable to examine the association between hospital volume and the outcomes. We then categorised the volume of patients into volume quarters, with the lowest volume quarter ( $<15$ patients/year) as the reference category. We chose volume quarters of patients to ensure a minimum number of hospitals in each volume category and to protect hospital identity. We also estimated the volume threshold above which an increase in volume was not associated with a reduction in the odds of an adverse outcome, by determining the change in the adjusted odds ratio associated with an increase in the pulmonary embolism volume by 10 cases. We defined the volume threshold as the annual hospital volume for which the relative change in the adjusted odds of the outcome associated with an increase of 10 patients with acute pulmonary embolism would be less than 0.01 (that is, an odds ratio more than 0.99). To characterise the variation of the estimated threshold, we used bootstrapping techniques and replicated this analysis in 500 bootstrap samples to obtain 95\% confidence intervals for the volume threshold.

\section{Study outcomes}

The primary outcome was mortality related to pulmonary embolism at 30 days after diagnosis of the condition. The secondary outcome was all cause mortality at 30 days. We also examined the rates of death (all cause and related to pulmonary embolism) within seven days following the diagnosis of pulmonary embolism. The RIETE investigators used medical record review to assess vital status. For patients who died, further medical record review (and proxy interviews when necessary) assisted with determining the date and cause of death. For deaths confirmed by autopsy or those following a clinically severe pulmonary embolism (either initially or shortly after an objectively confirmed recurrent event), in the absence of any alternative diagnosis, the investigators were instructed to judge death as due to fatal pulmonary embolism. We also examined the rates of non-fatal recurrence of venous thromboembolism, and non-fatal bleeding events within 30 days following the diagnosis of pulmonary embolism (see methods section in the supplementary appendix).

\section{Statistical analysis}

Because the proportions of missing data (for covariates) were below $5 \%$, we assumed that the missing data were unlikely to drive the results of our study and as such, we analysed the observed data (complete case analysis). We performed $\chi^{2}$ tests for categorical variables and analyses of variance for continuous variables to compare the demographic and clinical characteristics of patients across the quarters of hospital volume. We reported the use of reperfusion treatments for pulmonary embolism, and appropriate treatment in patients admitted to each quarter of hospitals.

To assess the relation between hospital volume and the outcomes of interest, we constructed hierarchical multivariable logistic regression models for the overall cohort. To address potential confounding due to case mix variation, we controlled for the severity of illness and additional variables related to the outcome of patients with acute pulmonary embolism. The following models were generated sequentially to determine the successive influence of potential confounders on the relation between hospital volume and mortality:

\section{- Unadjusted}

- Adjusted only for age and sex

- Adjusted for age, sex, and the following covariates: coexisting conditions (cancer, immobilisation, chronic lung disease, chronic heart disease), severity of pulmonary embolism (heart rate, systolic blood pressure), and laboratory results (creatinine levels, haemoglobin levels) at hospital admission

- Adjusted for age, sex, cancer, immobilisation, chronic lung disease, chronic heart disease, 
heart rate, systolic blood pressure, simplified pulmonary embolism severity index (sPESI), ${ }^{20}$ creatinine levels, and haemoglobin levels (predefined main analysis)

- Adjusted for age, sex, cancer, immobilisation, chronic lung disease, chronic heart disease, heart rate, systolic blood pressure, sPESI, creatinine levels, haemoglobin levels, and hospital status (university based or not).

All these models were built at the patient level, with hospital volume as a predictor variable with four categories. In all models, we accounted for clustering of patients within hospitals and hospitals clustered within countries. Interaction terms for year of diagnosis were included initially in the hospital level model, with a prespecified plan to remove this variable if no interaction was found.

We performed several sensitivity analyses. These analyses comprised the exclusion of outlier hospitals (those with too few or too many patients), exclusion of patients younger than 50 years old, exclusion of haemodynamically unstable patients, and exclusion of patients who received reperfusion treatments. Additional analyses included a falsification hypothesis analysis in which the cohort was evaluated for death related to cancer, chronic heart disease, and infection at 90 days. We also did alternative event rate estimation using inverse probability weighted regression adjustment (supplementary appendix). All analyses were conducted with Stata version 13.1 (Stata, College Station, TX, USA). All hypothesis tests were two sided, with a significance level of 0.05 .

\section{Patient and public involvement}

Patients were not involved in the design of this study, the choice of the outcome measures, or analysis of the data or dissemination. The study results will be available to patients, health professionals, and experts in the specialty through various channels: written communication, events and conferences, networks, social media, and patient-practitioner websites (including https://trombo. info/about-us/?lang=en, where some RIETE investigators share data with practitioners and patients).

\section{Results}

The study included 39257 patients with pulmonary embolism from 353 hospitals in 16 countries (fig 1). The linked data showed that the RIETE registry captured about $84 \%$ of the patients $(n=602 / 718)$ with a final diagnosis of pulmonary embolism from each hospital, with little variation according to hospital volume (table S1, supplemental appendix). Annual hospital volume ranged from one to 112 admitted patients with pulmonary embolism per year (median 7; interquartile range 4-16). The final cohort was divided into four quarters of hospital volume, roughly equally sized, with about 10000 patients in each quarter.

Patients admitted to higher volume hospitals and those admitted to lower volume hospitals differed in pre-existing medical conditions, and relevant clinical, physiological, and laboratory parameters. Patients admitted to higher volume hospitals were older, had more comorbid diseases (cancer, chronic lung disease, congestive heart failure, and recent bleeding), and more signs of clinical severity (high risk according to sPESI, tachycardia, hypoxaemia, and hypotension) than those admitted to lower volume hospitals (table 1). Regarding in-hospital reperfusion treatments, patients at low volume centres were more likely to receive reperfusion treatments (mostly systemic thrombolysis; $3.9 \% v 3.0 \%, \mathrm{P}<0.001)$ and less likely to receive an inferior vena cava filter $(2.7 \% v 3.3 \%$, $\mathrm{P}=0.006)$. Compared with those admitted to high volume hospitals, patients at low volume centres were more likely to receive management that did not adhere to clinical practice guidelines $(17.6 \%(\mathrm{n}=1512)$ $v$ 14.2\% ( $\mathrm{n}=1821), \mathrm{P}<0.001$; table $\mathrm{S} 2$, supplemental appendix).

The study had complete information on the primary outcome for all patients at the end of the 30 day follow-up. At 30 days, the entire cohort had an all cause mortality rate of 5.4\% (2139 of 39257 patients), and pulmonary embolism related mortality rate of $1.7 \%$ (668 of 39257 patients; table 2). When examined as a completely continuous variable (between 1 and 112), hospital volume was associated with a significant reduction in the adjusted odds of pulmonary embolism related mortality rates at 30 days $(\mathrm{P}=0.04$ for linear trend; fig 2). We saw no significant interaction between the volume-mortality relation and the year of pulmonary embolism diagnosis $(\mathrm{P}=0.99$ for interaction). There was not a specific volume threshold above which an increase in volume was not associated with a reduction in the odds of an adverse outcome. Compared with patients in the lowest quarter of hospital volume (quarter 1), patients in quarters 2,3 , and 4 had a reduction in the adjusted odds of pulmonary embolism related death at 30 days of 34\% ( $\mathrm{P}=0.06)$, 39\% $(\mathrm{P}=0.05)$, and 44\% ( $\mathrm{P}=0.03)$, respectively (table 3 and table $\mathrm{S} 3$ ). The adjusted risk of pulmonary embolism related death at 30 days was $2.3 \%$ for patients in the lowest volume quarter and $1.3 \%$ for patients in the highest volume quarter (table 3).

Adjusted all cause mortality at 30 days was 5.2\% for patients admitted to hospitals in the highest quarter and $6.4 \%$ for patients admitted to hospitals in the lowest quarter (table 3; odds ratio 0.78, 95\% confidence interval 0.50 to $1.22 ; \mathrm{P}=0.28$ ). Similar findings were observed for all cause mortality and pulmonary embolism related mortality at seven days. At seven days, the adjusted risk of pulmonary embolism related death was $1.7 \%$ for patients in the lowest quarter of hospital volume and $1.0 \%$ for patients in the highest quarter, and the adjusted risk of all cause mortality was $2.7 \%$ for patients in the lowest quarter and $2.1 \%$ for patients in the highest quarter (table 3). Among survivors, we saw no clear association between hospital volume and non-fatal recurrence or major bleeding. Compared with the lowest quarter of hospital volume, higher volume was 


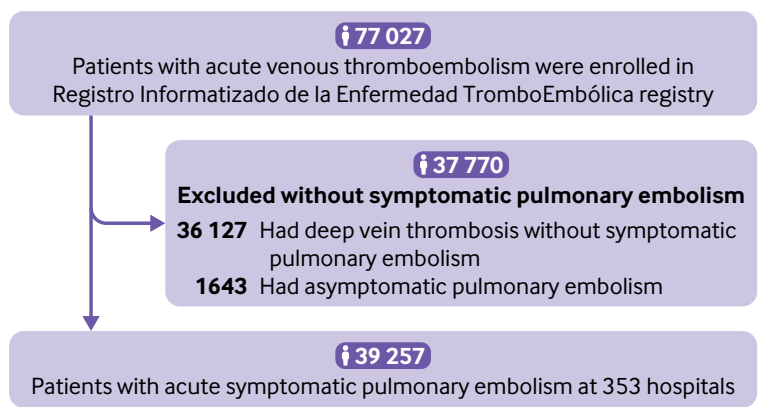

Fig 1 | STROBE study cohort flow diagram

not associated with a significant reduction in non-fatal recurrent venous thromboembolism in quarters 2, 3, and 4 (odds ratio 0.82 (95\% confidence interval 0.54 to 1.23 ), 0.74 (0.48 to 1.14 ), and 0.76 (0.49 to 1.19 ), respectively). We saw no significant difference in the incidence of non-fatal major bleeding events among hospital volume quarters (table 3).

To explore the sensitivity of our findings, we repeated the analysis with varying assumptions about the patient population and hospitals (table 4). Our results were not affected by the exclusion of younger patients (that is, age <50), haemodynamically unstable patients (that is, systolic blood pressure $<90 \mathrm{~mm} \mathrm{Hg}$ ), patients who received reperfusion treatments, or exclusion of outlier hospitals.

We performed a falsification hypothesis analysis using the outcome of mortality related to cancer, chronic heart disease, and infection at 90 days. Compared with patients in the lowest quarter of hospital volume (quarter 1), patients in quarters 2, 3 , and 4 did not have a significant reduction in the adjusted odds of death at 90 days related to cancer (odds ratio 1.52 (95\% confidence interval 1.06 to 2.19), 1.57 (1.05 to 2.33), and 1.52 (1.00 to 2.31), respectively), chronic heart disease (1.25 (0.65 to 2.40), 1.05 (0.52 to 2.09), and 0.86 (0.42 to 1.73), respectively), and infection (1.06 (0.61 to 1.82), 0.86 (0.48 to 1.55 ), and 1.34 (0.74 to 2.44 ), respectively; table S4, supplementary appendix). The propensity score analysis confirmed reduced mortality related to pulmonary embolism for patients admitted to high volume hospitals, thereby supporting the primary results (table S5, supplementary appendix).

\section{Discussion}

\section{Principal findings}

These data show an association between an increase in hospital volume of patients with pulmonary

\begin{tabular}{|c|c|c|c|c|}
\hline & \multicolumn{4}{|c|}{ Hospital volume } \\
\hline & Q1 (<15 patients/year) & Q2 (15-25 patients/year) & Q3 (>25-40 patients/year) & Q4 (>40 patients/year) \\
\hline \multicolumn{5}{|l|}{ Hospital characteristics } \\
\hline No of hospitals & 253 & 52 & 28 & 20 \\
\hline No of beds (mean (SD)) & $520(428)$ & $605(361)$ & $831(516)$ & $861(342)$ \\
\hline Teaching hospitals & $88(35)$ & $16(31)$ & $18(64)$ & $13(65)$ \\
\hline \multicolumn{5}{|l|}{ Patient characteristics } \\
\hline Patients & 8596 & 8130 & 9750 & 12781 \\
\hline Age (mean (SD)) & $65.6(17.6)$ & $67.2(16.9)$ & $68.0(16.4)$ & $67.7(16.7)$ \\
\hline Age $>80$ & $2024(23.5)$ & $2160(26.6)$ & $2670(27.4)$ & $3440(26.9)$ \\
\hline Male sex & $4050(47.1)$ & $3756(46.2)$ & $4593(47.1)$ & $5968(46.7)$ \\
\hline Weight (kg; mean (SD)) & $76.5(16.0)$ & $75.9(16.3)$ & $76.8(16.2)$ & $75.4(16.4)$ \\
\hline History of VTE & $5069(61.9)$ & $5339(67.8)$ & $6488(68.4)$ & $8931(71.1)$ \\
\hline Cancer $^{*}$ & $1751(20.4)$ & $1861(22.9)$ & $1875(19.2)$ & $3287(25.7)$ \\
\hline Recent surgeryt & $1010(11.7)$ & $898(11.0)$ & $1186(12.2)$ & $1504(11.8)$ \\
\hline Immobilisation for $\geq 4$ days $\ddagger$ & $2038(23.7)$ & $1894(23.3)$ & $2040(20.9)$ & $2852(22.3)$ \\
\hline Chronic lung disease & $1162(13.5)$ & $1142(14.0)$ & $1340(13.7)$ & $1918(15.0)$ \\
\hline Chronic heart disease & $705(8.2)$ & $718(8.8)$ & $808(8.3)$ & $1293(10.1)$ \\
\hline Recent major bleeding & $209(2.4)$ & $196(2.4)$ & $188(1.9)$ & $349(2.7)$ \\
\hline Pulse (beats; mean (SD)) & $93.0(19.7)$ & $91.9(20.0)$ & $91.8(20.0)$ & $93.5(20.2)$ \\
\hline Pulse $\geq 110$ beats $/ \mathrm{min}$ & $1744(21.4)$ & $1492(19.5)$ & $1903(19.7)$ & $2819(22.3)$ \\
\hline Systolic blood pressure (mm Hg; mean (SD)) & $128.3(23.7)$ & $130.6(23.1)$ & $130.3(24.3)$ & $128.6(24.5)$ \\
\hline Systolic blood pressure $<100 \mathrm{~mm} \mathrm{Hg}$ & $651(7.6)$ & $537(6.6)$ & $724(7.4)$ & $1217(9.5)$ \\
\hline Arterial oxyhaemoglobin saturation $<90 \%$ & $1971(38.5)$ & $1639(33.9)$ & $1947(32.3)$ & $3015(38.4)$ \\
\hline \multicolumn{5}{|l|}{ SPESI $\left.\right|^{20}$} \\
\hline Low risk & $2755(32.0)$ & $2502(30.8)$ & $3193(32.7)$ & $3586(28.1)$ \\
\hline High risk & $5841(68.0)$ & $5628(69.2)$ & $6557(67.3)$ & $9195(71.9)$ \\
\hline Abnormal creatinine levels $(>176.8 \mu \mathrm{mol} / \mathrm{L})$ & $1505(18.2)$ & $1542(20.1)$ & $1971(20.6)$ & $2381(18.9)$ \\
\hline Haemoglobin (g/L; mean (SD)) & $130(21)$ & $130(21)$ & $131(20)$ & $130(20)$ \\
\hline Inappropriate management§ & $1512(17.6)$ & $1251(15.4)$ & $1453(14.9)$ & $1821(14.2)$ \\
\hline Reperfusion treatment & $334(3.9)$ & $206(2.5)$ & $326(3.3)$ & $383(3.0)$ \\
\hline IVC filter insertion & $230(2.7)$ & $224(2.8)$ & $255(2.6)$ & $423(3.3)$ \\
\hline
\end{tabular}




\begin{tabular}{|c|c|c|c|c|}
\hline \multirow{2}{*}{$\begin{array}{l}\text { Overall/total No (\%) } \\
\text { of patients }\end{array}$} & \multicolumn{4}{|c|}{ Hospital volume } \\
\hline & Q1 (<15 patients/year) & Q2 (15-25 patients/year) & Q3 (>25-40 patients/year) & Q4 (>40 patients/year) \\
\hline \multicolumn{5}{|l|}{ Mortality } \\
\hline 30 day $P E$ related mortality & $201 / 8596(2.3)$ & $125 / 8130(1.5)$ & $148 / 9750(1.5)$ & $194 / 12781(1.5)$ \\
\hline 30 day all cause mortality & $525 / 8596(6.1)$ & $433 / 8130(5.3)$ & 459/9750 (4.7) & $722 / 12781(5.6)$ \\
\hline 7 day PE related mortality & $153 / 8596(1.8)$ & $91 / 8130(1.1)$ & $110 / 9750(1.1)$ & $154 / 12781(1.2)$ \\
\hline 7 day all cause mortality & $236 / 8596(2.7)$ & $169 / 8130(2.1)$ & $191 / 9750(2.0)$ & $291 / 12781(2.3)$ \\
\hline \multicolumn{5}{|l|}{ Non-fatal complications } \\
\hline 30 day VTE recurrence & $94 / 8596(1.1)$ & $69 / 8130(0.8)$ & $75 / 9750(0.8)$ & $125 / 12781(1.0)$ \\
\hline 30 day major bleeding & $299 / 8596(3.5)$ & $270 / 8130(3.3)$ & $352 / 9750(3.6)$ & 496/12781(3.9) \\
\hline
\end{tabular}

embolism and a lower risk adjusted mortality related to pulmonary embolism at 30 days. We observed a consistent dose-response relation between hospital volume and pulmonary embolism related mortality. The results were consistent with use of various adjustment techniques, across major subgroups of the patient populations and modelling assumptions, and were less likely to be driven by unmeasured confounding, represented by the lack of association between hospital volume of patients with pulmonary embolism and the falsification endpoints.

\section{Comparison with other studies}

Few studies have investigated whether hospitals that care for large numbers of patients with pulmonary embolism have a lower short term mortality than those caring for low numbers of such patients. ${ }^{6}$ In a study of 10354 patients admitted to hospital for pulmonary embolism based on administrative data from 186 Pennsylvania hospitals, Aujesky and colleagues found that the hospitals with higher annual volumes $(\geq 42$ patients/year) of patients with pulmonary embolism had significantly lower in-hospital and all cause mortality at 30 days than the hospitals with very low volumes (<10 patients/year). Our study's large sample size, availability of good quality clinical data that allowed for adjustment for potential confounders, availability of cause specific mortality, availability of falsification endpoints, and robustness of the findings across multiple sensitivity analyses provide evidence supporting the concept that patients with acute symptomatic pulmonary embolism admitted to high

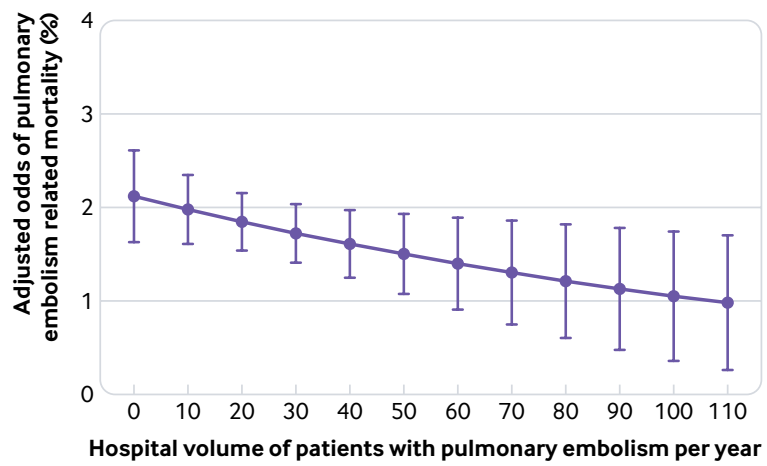

Fig 2 | Relation between hospital volume and pulmonary embolism related mortality. Data are adjusted odds ratios ( $95 \%$ confidence intervals) volume hospitals are more likely to survive than those admitted to low volume hospitals.

\section{Meaning of the study}

The relation between hospital volume of pulmonary embolism and outcome among patients with acute pulmonary embolism could have several explanations. Medical teams at low volume hospitals could be less experienced in providing care to patients with pulmonary embolism (including lack of timely recognition of clinical deterioration, lack of multidisciplinary efforts to stabilise the patients such as the use of pulmonary embolism response teams (PERTs), or lack of adherence to guidelines and available evidence for routine or advanced treatments), which could lead to worse outcomes in patients at such institutions. In fact, our study showed that clinicians at low volume hospitals adhered to evidence based guidelines less frequently, which has been shown to correlate with patient outcomes. ${ }^{21}$

Our findings have implications on how best to manage patients with acute symptomatic pulmonary embolism in the future. Educational strategies could be developed towards improving the knowledge and clinical expertise of physicians from low volume hospitals. Improved knowledge is particularly important because we observed evidence of both overtreatment and undertreatment with reperfusion treatments for pulmonary embolism in low volume hospitals (table S2). Thus, initiatives that could help improve the practitioners' knowledge and adherence to guidelines recommendations at low volume hospitals, timely transfer of patients with pulmonary embolism (especially severe cases) to high volume hospitals, and dissemination of PERT teams across the hospitals (such as multidisciplinary teams caring for patients with ST elevation myocardial infarction) could be considered. Currently, little evidence exists on the benefits of PERT teams for improving patient outcomes, quality of life, and cost. ${ }^{22-25}$ Findings from our study would reinforce the interest in this area, which deserves focused investigations.

\section{Strengths and limitations of study}

Our study had several potential limitations. Firstly, despite our best efforts, the possibility of residual confounding still remains. Nevertheless, we did adjust for age, sex, comorbidities, severity of pulmonary embolism, and laboratory results, and still found 


\begin{tabular}{|c|c|c|c|c|}
\hline \multirow[b]{2}{*}{ Variable } & \multicolumn{4}{|c|}{ Hospital volume } \\
\hline & Q1 (<15 patients/year) & Q2 (15-25 patients/year) & Q3 (>25-40 patients/year) & Q4 (>40 patients/year) \\
\hline \multicolumn{5}{|l|}{ Odds ratio $(95 \% \mathrm{Cl}) \dagger$} \\
\hline 30 day $P E$ related mortality & 1.0 & $0.66(0.43$ to 1.01$)$ & 0.61 (0.38 to 0.99$)$ & $0.56(0.33$ to 0.95$)$ \\
\hline 30 day all cause mortality & 1.0 & 0.68 (0.48 to 0.97$)$ & $0.73(0.19$ to 1.10$)$ & $0.78(0.50$ to 1.22$)$ \\
\hline 7 day PE related mortality & 1.0 & $0.65(0.41$ to 1.02$)$ & $0.68(0.42$ to 1.11$)$ & $0.60(0.35$ to 1.03$)$ \\
\hline 7 day all cause mortality & 1.0 & $0.72(0.48$ to 1.07$)$ & $0.72(0.46$ to 1.12$)$ & $0.76(0.47$ to 1.24$)$ \\
\hline 30 day non-fatal VTE recurrence & 1.0 & $0.82(0.54$ to 1.23$)$ & $0.74(0.48$ to 1.14$)$ & $0.76(0.49$ to 1.19$)$ \\
\hline 30 day non-fatal major bleeding & 1.0 & $0.92(0.70$ to 1.20$)$ & $0.90(0.66$ to 1.22$)$ & $1.07(0.77$ to 1.47$)$ \\
\hline \multicolumn{5}{|l|}{ Adjusted risk (\%; 95\% Cl) $\ddagger$} \\
\hline 30 day PE related mortality & $2.3(1.8$ to 2.8$)$ & $1.5(1.0$ to 2.1$)$ & $1.4(0.9$ to 2.0$)$ & $1.3(0.7$ to 1.9$)$ \\
\hline 30 day all cause mortality & $6.4(5.4$ to 7.3$)$ & $4.7(3.5$ to 5.8$)$ & $4.9(3.5$ to 6.4$)$ & $5.2(3.4$ to 7.0$)$ \\
\hline 7 day PE related mortality & $1.7(1.3$ to 2.1$)$ & $1.1(0.7$ to 1.5$)$ & $1.2(0.7$ to 1.6$)$ & $1.0(0.6$ to 1.5$)$ \\
\hline 7 day all cause mortality & $2.7(2.1$ to 3.2$)$ & $2.0(1.4$ to 2.6$)$ & $2.0(1.3$ to 2.7$)$ & 2.1 (1.3 to 2.9$)$ \\
\hline 30 day non-fatal VTE recurrence & $1.1(0.8$ to 1.4$)$ & $0.9(0.5$ to 1.1$)$ & $0.8(0.5$ to 1.1$)$ & $0.8(0.5$ to 1.2$)$ \\
\hline 30 day non-fatal major bleeding & $3.6(3.1$ to 4.2$)$ & $3.2(2.5$ to 3.9$)$ & $3.8(2.9$ to 4.7$)$ & $3.9(2.8$ to 4.9$)$ \\
\hline
\end{tabular}

a consistent relation between hospital volume and outcome. The severity of pulmonary embolism might have accounted for some of the differences between the groups' outcomes. However, because patients admitted to higher volume hospitals had more signs of clinical severity, the study findings suggest that the design might have caused a bias against hospital volume. Furthermore, the results of sensitivity analyses and falsification hypothesis analyses made it less likely that our results were driven by unmeasured residual confounding, and provided evidence of the robustness of the findings. In addition, the single data point of initial blood pressure and heart rate used to define severity could have affected our analysis. However, based on current guidelines and the published literature, prognostication of pulmonary embolism is based on the findings at the time of pulmonary embolism diagnosis.

Secondly, similar to most studies looking into an association between volume and outcomes, our analysis cannot determine the direction of the association (that is, causality). ${ }^{26}$ Although high volume hospitals had better adherence to guideline recommendations in our study, their good quality of care might have been a driver in attracting more patients with pulmonary embolism, thereby increasing their volume. Additional qualitative and mixed methods research is needed to further understand the reasons for better outcomes in high volume centres, and the major areas for improvement in low volume centres. Although this study was performed over a long period of time, we did not find significant interaction between the volume-mortality relation and year of pulmonary embolism diagnosis. Finally, because our study cohort probably included hospitals that were enthusiastic about evidence based management of pulmonary embolism, reductions in mortality associated with increases in the annual volume of patients treated could be more pronounced compared with other hospitals where vested teams of motivated physicians for pulmonary embolism management do not exist. However, the RIETE registry is the only large scale, multinational, observational study of the spectrum of patients diagnosed with a pulmonary embolism, with continuous recruitment of patients for more than 10 years, and offers a unique opportunity to look at a large number of patients in various treatment settings, countries, and continents over a long period of time.

\section{Conclusions and policy implications}

We observed an inverse association between annual hospital volume of pulmonary embolism and outcomes among patients with acute symptomatic pulmonary

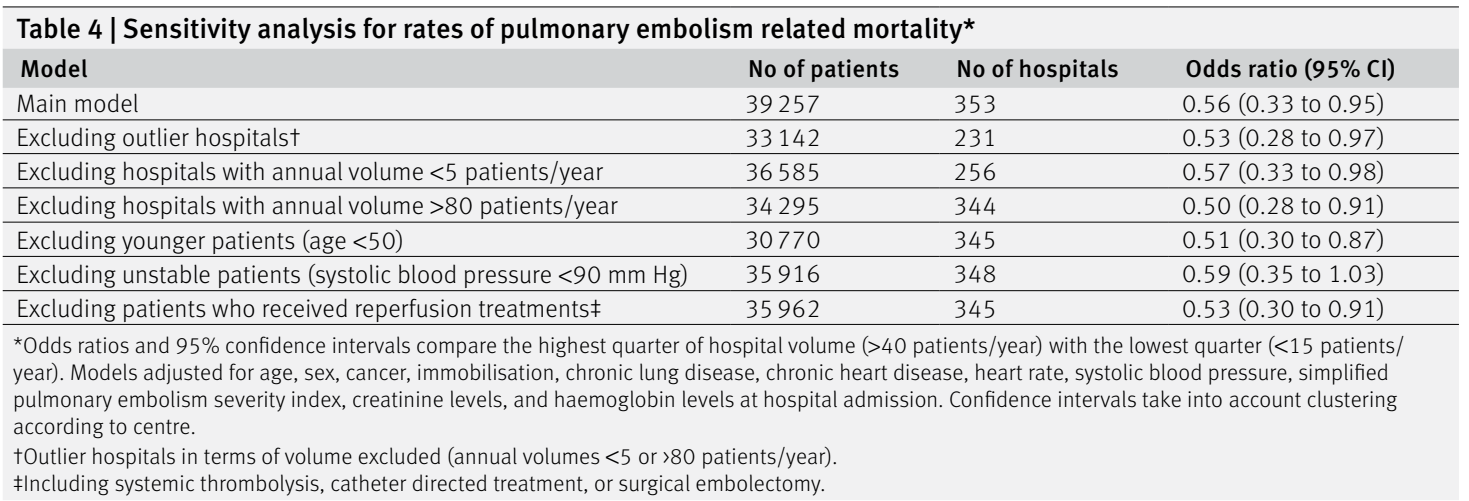


embolism. Additional research is needed to investigate whether developing strategies to improve the clinical expertise of low volume clinicians, triage and transfer of select high risk patient subgroups, and use of PERTs might lead to better patient outcomes.

\author{
AUTHOR AFFILIATIONS \\ ${ }^{1}$ Respiratory Department, Ramón y Cajal Hospital, Ramón y Cajal \\ Institute for Health Research (IRYCIS), Madrid 28034, Spain \\ ${ }^{2}$ Medicine Department, Alcalá University, Madrid, Spain \\ ${ }^{3}$ Division of Cardiology, Department of Medicine, Columbia \\ University Medical Center, New York Presbyterian Hospital, New \\ York, NY, USA \\ ${ }^{4}$ Center for Outcomes Research and Evaluation, Yale University \\ School of Medicine, New Haven, CT, USA \\ ${ }^{5}$ Cardiovascular Research Foundation, New York, NY, USA \\ ${ }^{6}$ Biostatistics Department, Ramón y Cajal Hospital, Ramón y Cajal \\ Institute for Health Research (IRYCIS), CIBERESP, Madrid, Spain \\ ${ }^{7}$ Respiratory Department, Araba Hospital, Vitoria, Spain \\ ${ }^{8}$ Respiratory Department, Gregorio Marañón Hospital, Madrid, Spain \\ ${ }^{9}$ Respiratory Department, Virgen del Rocío Hospital, Institute of \\ Biomedicine of Seville, CIBERES, Seville, Spain \\ ${ }^{10}$ Department of Internal Medicine, Clinica Universidad de Navarra, \\ Madrid, Spain \\ ${ }^{11}$ Divisions of Pulmonary and Critical Care Medicine and General \\ Medical Sciences, Washington University School of Medicine, St \\ Louis, MO, USA \\ ${ }^{12}$ Department of Internal Medicine, Germans Trias i Pujol University \\ Hospital, Badalona, Spain \\ ${ }^{13}$ Catholic University of Murcia, Murcia, Spain
}

We thank Sanofi Spain for supporting this registry with an unrestricted educational grant; Bayer Pharma AG for supporting this registry (limited to the part of RIETE outside Spain, which accounts for a $25.29 \%$ of the total patients included in the registry); and the RIETE registry coordinating centre, S\&H Medical Science Service, for their quality control data, logistic support, and administrative support. Contributors: DJ and BB contributed equally to the manuscript. DJ, $B B, A Q$, and $M M$ were responsible for the study concept and design. DJ, BB, AQ, AM, JLL, JdM-D, LJ-P, PR-A, RDY, and MM contributed to the acquisition of data, analysis and interpretation of data, and statistical analysis. DJ, BB, AQ, RDY, and MM drafted the manuscript. DJ, BB, AQ, AM, JLL, JdM-D, LJ-P, PR-A, RDY, and MM critically revised the manuscript for important intellectual content. DJ and MM supervised the study. All authors had full access to the data and take responsibility for the integrity of the data and accuracy of the analysis. The corresponding author attests that all listed authors meet authorship criteria and that no others meeting the criteria have been omitted. DJ is guarantor.

Funding: This study received no specific funding

Competing interests: All authors have completed the ICMJE uniform disclosure form at www.icmje.org/coi_disclosure.pdf and declare: no support from any organisation for the submitted work; DJ has served as an adviser or consultant for Bayer HealthCare Pharmaceuticals, Boehringer Ingelheim, Bristol-Myers Squibb, Daiichi Sankyo, Leo Pharma, Pfizer, Rovi, and Sanofi; served as a speaker or a member of a speakers' bureau for Bayer HealthCare Pharmaceuticals, Boehringe Ingelheim, Bristol-Myers Squibb, Daiichi Sankyo, Leo Pharma, Rovi, and Sanofi; and received grants for clinical research from Daiichi Sankyo, Sanofi, and Rovi; BB was supported by the National Heart, Lung, and Blood Institute, National Institutes of Health (grant T32 HL007854; the content is solely the responsibility of the authors and does not necessarily represent the official views of the Nationa Institutes of Health) and reports serving as a consulting expert (on behalf of the plaintiff) for a litigation related to inferior vena caval filters; LJ-P has served as an adviser or consultant for Actelion Pharmaceuticals, Bayer HealthCare Pharmaceuticals, Leo Pharma, Menarini, Pfizer, and Rovi; in the past three years, RDY has received research funding from Bayer HealthCare Pharmaceuticals, BristolMyers Squibb, Pfizer, and Portola, and has served as a consultant for Bayer HealthCare, Bristol-Myers Squibb, Glaxo-Smithkline, Janssen, Johnson and Johnson, Ortho Pharmaceuticals, Organon, Pfizer, Portola, Sanofi, and Scios; MM has served as an adviser or consultant for Bayer HealthCare Pharmaceuticals, Daiichi Sankyo, Leo Pharma, and Sanofi; served as a speaker or a member of a speakers' bureau for Bayer HealthCare Pharmaceuticals, Daiichi Sankyo, Leo Pharma, and Sanofi; and received grants for clinical research from Sanofi and Bayer; the other authors declare no other relationships or activities that could appear to have influenced the submitted work.

Ethical approval: All patients provided written or oral consent for participation in the registry in accordance with local ethics committee requirements.

Data sharing: No additional data available.

The lead author affirms that the manuscript is an honest, accurate, and transparent account of the study being reported; that no important aspects of the study have been omitted; and that any discrepancies from the study as planned have been explained.

This is an Open Access article distributed in accordance with the Creative Commons Attribution Non Commercial (CC BY-NC 4.0) license, which permits others to distribute, remix, adapt, build upon this work non-commercially, and license their derivative works on different terms, provided the original work is properly cited and the use is noncommercial. See: http://creativecommons.org/licenses/by-nc/4.0/.

1 Bělohlávek J, Dytrych V, Linhart A. Pulmonary embolism, part I: Epidemiology, risk factors and risk stratification, pathophysiology, clinical presentation, diagnosis and nonthrombotic pulmonary embolism. Exp Clin Cardiol 2013;18:129-38.

2 Heit JA. The epidemiology of venous thromboembolism in the community. Arterioscler Thromb Vasc Biol 2008;28:370-2. doi:10.1161/ATVBAHA.108.162545

3 Kumbhani DJ, Fonarow GC, Heidenreich PA, et al. Association between hospital volume, processes of care, and outcomes in patients admitted with heart failure: insights from get with the guidelines-heart failure. Circulation 2018;137:1661-70. doi:10.1161/CIRCULATIONAHA.117.028077

4 Tu JV, Austin PC, Chan BTB. Relationship between annual volume of patients treated by admitting physician and mortality after acute myocardial infarction. JAMA 2001;285:3116-22. doi:10.1001/ jama.285.24.3116

5 Ko DT, Dattani ND, Austin PC, et al. Emergency department volume and outcomes for patients after chest pain assessment. Circ Cardiovasc Qual Outcomes 2018;11:e004683. doi:10.1161/ CIRCOUTCOMES.118.004683

6 Aujesky D, Mor MK, Geng M, Fine MJ, Renaud B, Ibrahim SA. Hospital volume and patient outcomes in pulmonary embolism. CMA/ 2008;178:27-33. doi:10.1503/cmaj.070743

7 Meyer G, Vicaut E, Danays T, et al, PEITHO Investigators. Fibrinolysis for patients with intermediate-risk pulmonary embolism. N EnglJ Med 2014;370:1402-11. doi:10.1056/NEJMoa1302097

8 Sharifi M, Bay C, Skrocki L, Rahimi F, Mehdipour M, "MOPETT" Investigators. Moderate pulmonary embolism treated with thrombolysis (from the "MOPETT" Trial). Am J Cardiol 2013;111:2737. doi:10.1016/j.amjcard.2012.09.027

9 Kucher N, Boekstegers P, Müller OJ, et al. Randomized, controlled trial of ultrasound-assisted catheter-directed thrombolysis for acute intermediate-risk pulmonary embolism. Circulation 2014;129:47986. doi:10.1161/CIRCULATIONAHA.113.005544

10 Leacche M, Unic D, Goldhaber SZ, et al. Modern surgical treatment of massive pulmonary embolism: results in 47 consecutive patients after rapid diagnosis and aggressive surgical approach. J Thorac Cardiovasc Surg 2005;129:1018-23. doi:10.1016/j. jtcvs.2004.10.023

11 Laporte S, Mismetti P, Décousus H, et al, RIETE Investigators. Clinical predictors for fatal pulmonary embolism in 15,520 patients with venous thromboembolism: findings from the Registro Informatizado de la Enfermedad TromboEmbolica venosa (RIETE) Registry. Circulation 2008;117:1711-6. doi:10.1161/ CIRCULATIONAHA.107.726232

12 Muriel A, Jiménez D, Aujesky D, et al, RIETE Investigators. Survival effects of inferior vena cava filter in patients with acute symptomatic venous thromboembolism and a significant bleeding risk. J Am Coll Cardiol 2014;63:1675-83. doi:10.1016/j.jacc.2014.01.058

13 Monreal M, Kakkar AK, Caprini JA, et al, RIETE Investigators. The outcome after treatment of venous thromboembolism is different in surgical and acutely ill medical patients. Findings from the RIETE registry. J Thromb Haemost 2004;2:1892-8. doi:10.1111/j.15387836.2004.01012.x

14 Riera-Mestre A, Jiménez D, Muriel A, et al, RIETE investigators. Thrombolytic therapy and outcome of patients with an acute symptomatic pulmonary embolism. I Thromb Haemost 2012;10:7519. doi:10.1111/j.1538-7836.2012.04698.x

15 Bikdeli B, Jimenez D, Hawkins M, et al, RIETE Investigators. Rationale, design and methodology of the computerized registry of patients with venous thromboembolism (RIETE). Thromb Haemost 2018;118:214-24. doi:10.1160/TH17-07-0511

16 Guijarro R, Montes J, Sanromán C, Monreal M, RIETE Investigators. Venous thromboembolism in Spain. Comparison between an 
administrative database and the RIETE registry. Eur J Intern Med 2008;19:443-6. doi:10.1016/j.ejim.2007.06.026

17 Remy-Jardin M, Remy J, Wattinne L, Giraud F. Central pulmonary thromboembolism: diagnosis with spiral volumetric CT with the single-breath-hold technique--comparison with pulmonary angiography. Radiology 1992;185:381-7. doi:10.1148/ radiology.185.2.1410342

18 PIOPED Investigators. Value of the ventilation/perfusion scan in acute pulmonary embolism. Results of the prospective investigation of pulmonary embolism diagnosis (PIOPED). JAMA 1990;263:2753-9. doi:10.1001/jama.1990.03440200057023

19 Kearon C, Ginsberg JS, Hirsh J. The role of venous ultrasonography in the diagnosis of suspected deep venous thrombosis and pulmonary embolism. Ann Intern Med 1998;129:1044-9. doi:10.7326/00034819-129-12-199812150-00009

20 Jiménez D, Aujesky D, Moores L, et al, RIETE Investigators. Simplification of the pulmonary embolism severity index for prognostication in patients with acute symptomatic pulmonary embolism. Arch Intern Med 2010;170:1383-9. doi:10.1001/ archinternmed.2010.199

21 Jiménez D, Bikdeli B, Barrios D, et al, RIETE investigators. Management appropriateness and outcomes of patients with acute pulmonary embolism. Eur Respir / 2018;51:1800445. doi:10.1183/13993003.00445-2018
22 Rosovsky R, Chang Y, Rosenfield K, et al. Changes in treatment and outcomes after creation of a pulmonary embolism response team (PERT), a 10-year analysis [correction in: / Thromb Thrombolysis 2019;47:41]. J Thromb Thrombolysis 2019;47:31-40. doi:10.1007/ s11239-018-1737-8

23 Kabrhel C, Rosovsky R, Channick R, et al. A multidisciplinary pulmonary embolism response team: initial 30-month experience with a novel approach to delivery of care to patients with submassive and massive pulmonary embolism. Chest 2016;150:384-93. doi:10.1016/j.chest.2016.03.011

24 Carroll BJ, Pemberton H, Bauer KA, et al. Initiation of a multidisciplinary, rapid response team to massive and submassive pulmonary embolism. Am J Cardiol 2017;120:1393-8. doi:10.1016/j.amjcard.2017.07.033

25 Serhal M, Haddadin IS, Heresi GA, Hornacek DA, Shishehbor MH, Bartholomew JR. Pulmonary embolism response teams. I Thromb Thrombolysis 2017;44:19-29. doi:10.1007/s11239-017-1498-9

26 Luft HS, Hunt SS, Maerki SC. The volume-outcome relationship: practice-makes-perfect or selective-referral patterns?Health Serv Res 1987;22:157-82.

Web appendix: Supplementary appendix 